\title{
Analisis Penerapan Biaya Relevan Dalam Pengambilan Keputusan Menerima Atau Menolak Pesanan Khusus Pada Perusahaan Meubel CV. Citra Jati Jepara
}

\author{
FAHMI OEMAR $^{1}$; DAVIT OKTAVIAN ${ }^{2}$ \\ Universitas Lancang Kuning \\ Jln. Yos Sudarso KM 08 Rumbai Telp. (0962) 52581 \\ E-mail : Fahmi_Pala@yahoo.com
}

\begin{abstract}
The growth of a business entity is usually inseparable from various problems faced by the company. Problems that arise are very diverse, including the problems in decision making. Various information is needed by management in choosing the right decision. One of the important information for planning and decision making is regarding relevant cost analysis information. The purpose of this study is to determine the calculation of relevant costs made by company management in making decisions to accept or reject special orders. The analytical method used in this research is quantitative descriptive method. The results of the study indicate that the company has not applied the relevant cost analysis in calculating the cost of production for a special order. The results of the analysis of relevant costs, especially the decision making to accept or reject special orders indicate that the proposed alternatives are able to provide benefits for the company when receiving special orders. Management CV. Jati Jepara imagery should apply relevant cost analysis so that special orders can be an alternative to increase company profits.
\end{abstract}

Keywords: Relevant Costs, Decision Making, Special Orders

Dalam dunia usaha sekarang yang semakin bertambah banyak, persaingan antara perusahaan-perusahaan juga semakin meningkat. Daya saing yang semakin kompetitif menyiratkan bahwa setiap perusahaan harus lebih efisien agar dapat bertahan didalam dunia bisnis. Salah satu usaha untuk meningkatkan efisiensi perusahaan agar dapat bersaing dengan kompetitor-kompetitor lainnya maka perusahan tersebut harus memproduksi barang yang berkualitas dan juga dengan harga yang rendah.

Informasi tentang biaya relevan menjadi hal yang sangat penting dan senantiasa diperlukan oleh pihak manajemen dalam pengambilan keputusan yang tepat. Biaya relevan sering kali disebut dengan biaya masa yang akan datang. Seluruh keputusan yang diambil berhubungan dengan masa yang akan datang. Setiap keputusan yang diambil oleh pihak manajemen akan menjadi tolak ukur keberhasilan suatu perusahaan di masa yang akan datang.
Biaya relevan merupakan biaya masa depan yang berbeda pada setiap alternatif. Semua keputusan berhubungan dengan masa depan sehingga hanya biaya masa depan yang dapat menjadi relevan dengan keputusan (Hansen dan Mowen; 2013).

Penggunaan biaya relevan di dalam penyelesaian berbagai persoalan yang dihadapi perusahaan akan sangat bermanfaat bagi pengambilan keputusan perusahaan. Karena tanpa mempergunakan metode biaya relevan ini, ada kemungkinan beberapa persoalan yang dihadapi perusahaan dapat berakibat pada pemilihan jalan keluar dan keputusan yang salah oleh pihak manajemen perusahaan. Terdapat beberapa persoalan yang dapat diselesaikan dengan metode ini, antara lain meliputi: (1) Membuat atau membeli, (2) Meneruskan atau menghentikan, (3) Menjual atau memproses lebih lanjut dan (4) Menerima atau menolak pesanan khusus. (Kamaruddin; 2013). 
Tujuan yang ingin dicapai dari penelitian ini adalah untuk menganalisis perhitungan biaya relevan dalam pengambilan keputusan menerima atau menolak pesanan khusus pada perusahaan meubel CV. Citra Jati Jepara.

Akuntansi manajerial adalah kegiatan yang memberikan informasi keuangan dan non keuangan untuk manajer organisasi dan pengambil keputusan internal lainnya (Wild dan Shaw;2010)

Akuntansi manajemen (management accounting) adalah suatu profesi yang melibatkan kemitraan dalam pengambilan keputusan manajemen, menyusun perencanaan dan sistem manajemen kinerja, serta menyediakan keahlian dalam pelaporan keuangan dan pengendalian untuk membantu manajemen dalam memformulasikan mengimplementasikan suatu strategi organisasi (Blocher dkk;2011).

Akuntansi biaya adalah bagian dari akuntansi manajemen dimana merupakan salah satu dari bidang khusus akuntansi yang menekankan pada penentuan dan pengendalian biaya (Firdaus dan Abdullah;2014)

Biaya adalah kas atau ekuivalen yang di korbankan untuk membeli barang atau jasa yang di harapkan akan memberikan manfaat bagi perusahaan saat sekarang atau untuk periode mendatang (Krismiaji;2011). Biaya adalah pengorbanan sumber ekonomi, yang di ukur dalam satuan uang, yang telah terjadi atau yang kemungkinan akan terjadi untuk tujuan tertentu (Mulyadi;2012).

Akuntansi biaya bertujuan menyediakan informasi biaya yang berkualitas bagi manajemen dalam rangka perencanaan, pengendalian, dan pengambilan keputusan. Oleh karena itu, biaya perlu diklasifikasikan atau digolongkan sesuai tujuannya, yakni untuk apa biaya tersebut digunakan. Klasifikasi adalah proses pengelompokkan dari seluruh komponen secara lebih ringkas dan sistematis agar dapat memberikan informasi yang lebih akurat (bermanfaat dan berarti). Dalam pengklasifikasian biaya dikenal konsep "beragam biaya untuk tujuan yang berbeda (different cost for different purpose)".

Biaya relevan adalah biaya yang berubah atau berbeda diantara keputusan yang satu dengan yang lain, apabila biayanya tidak berubah atau sama saja di antara beberapa keputusan yang diambil, maka dikatakan biaya tidak relevan (Setiawan;2014).

Perhitungan biaya relevan merupakan nilai dalam pemecahan mengenai jenis masalah. Secara tradisional, aplikasi biaya relevan dalam pengambilan keputusan menjelaskan penerapan analisis biaya relevan dapat bermanfaat bagi manajemen dalam pengambilan keputusan. Berikut merupakan jenis-jenis keputusan dalam analisis biaya relevan yaitu: membuat atau membeli; meneruskan atau menghentikan; menjual atau memproses lebih lanjut; dan menerima atau menolak pesanan khusus. (Kamaruddin;2013)

Kadang-kadang perusahaan perlu melakukan diskriminasi harga untuk memperoleh keuntungan maksimum atau untuk menekan kerugian. Namun kebijakan ini hanya dilakukan pada kondisi khusus, yaitu jika perusahan memiliki kapasitas menganggur, maka perusahaan dalam kondisi yang tidak optimal, karena perusahaan mengeluarkan biaya tetap dalam jumlah banyak, sementara perolehan pendapatannya tidak proporsional dengan biaya tetap tersebut. Untuk mengurangi kerugian ini, perusahaan dapat memanfaatkannya dengan menerima pesanan khusus. Dengan kata lain, pesanan khusus biasanya diterima dengan memanfaatkan fasilitas menganggur. Selain itu, perusahaan hanya melayani pesanan khusus ini untuk para pelanggan tertentu saja karena harga yang ditetapkan untuk pesanan khusus biasanya di bawah harga pasar. Jika pesanan ini tidak dibatasi, maka kebijakan diskriminasi harga ini 
justru akan merusak pangsa pasar. (Hidayat;2014)

Penelitian terdahulu yang di lakukan oleh Dewanti Rantung dan Lidia Mawikere (2014) dengan judul penelitian penerapan biaya relevan dalam pengambilan keputusan menerima atau menolak pesanan khusus pada CV. Tabea. Hasil analisis menunjukkan perusahaan dapat menerima pesanan khusus dari klien karena dapat memberikan keuntungan dan sesuai dengan kriteria pesanan khusus yaitu harga jual pesanan khusus lebih tinggi dari pada biaya variabel.

Dan begitu juga hasil penelitan ini mempunyai kesamaan dengan penelitian yang dilakukan oleh Octavianus Macpal dan Ventje Ilat (2014) yang berjudul Analisis Biaya Relevan Untuk Menerima Atau Menolak Pesanan Khusus Pada UD. Sinar Sakti. Hasil yang di peroleh dari penelitian Octavianus Macpal dan Ventje Ilat menunjukkan bahwa analisis biaya relevan sangat bermanfaat untuk diterapkan dalam perusahaan pada beberapa kesempatan tertentu.Alternatif ini berpengaruh dalam laba perusahaan apabila perusahaan menerima pesanan khusus.

Demikian juga penelitian yang dilakukan oleh Rahmat Hidayat (2014) yang berjudul Analisis Penerapan Biaya Relevan Dalam Menerima Atau Menolak Pesanan Khusus Pada UD.Rezky Bakery. Hasil dari penelitian Rahmad Hidayat adalah analisis biaya relevan sangat bermanfaat untuk diterapkan pada beberapa kesempatan tertentu. Penerapan perhitungan ini akan berpengaruh pada laba perusahaan apabila perusahaan mampu menerapkan dengan benar terlebih pada saat adanya pesanan khusus.

\section{METODE}

Data kualitatif adalah data yang tidak berwujud angka atau data yang disajikan dalam bentuk kata-kata yang mengandung makna dan tidak dapat dikuantitatifkan. Jenis data seperti ini berupa sejarah singkat perusahaan, struktur organisasi, proses pelaksanaan produksi dan informasi lainnya yang relevan dengan penulisan ini. Data kuantitatif adalah data yang berwujud angka. Jenis data seperti ini berupa data yang berhubungan dengan penerapan biaya relevan dalam pengambilan keputusan menerima atau menolak pesanan khusus seperti harga jual, jumlah produksi, biaya produksi, pendapatan perusahaan serta data lainnya yang dapat menunjang pokok pembahasan penelitian ini.

Data primer adalah sumber data penelitian yang diperoleh secara langsung dari sumber asli dalam bentuk data mentah yang belum diolah seperti observasi dan wawancara. Data sekunder adalah data yang diperoleh secara tidak langsung, data sekunder dalam penelitian ini berasal dari buku-buku dan artikel-artikel yang berhubungan dengan judul penelitian ini.

Wawancara, adalah suatu teknik pengumpulan data dengan melaksanakan tanyajawab langsung kepada staf yang mempunyai wewenang untuk memberikan data dan informasi yang diperlukan dalam penulisan. Observasi, adalah teknik pengumpulan data dengan mengadakan pengamatan secara langsung pada CV. Citra Jati Jepara. Dokumentasi, adalah cara pengumpulan data melalui berupa arsiparsip perhitungan biaya produksi dan lainlain yang berhubungan dengan masalah penelitian.

Analisis data yang dilakukan dalam penelitian ini adalah analisis deskriptif, dimana tujuan dari analisis ini adalah untuk membuat perhitungan biaya relevan dalam pengambilan keputusan menerima atau menolak pesanan khusus.Berdasarkan perhitungan biaya relevan tersebut, maka peneliti dapat menentukan alternatif mana yang terbaik diantara menerima atau menolak pesanan khusus (pengambilan keputusan) dalam rangka pencapaian laba yang memadai.

\section{HASIL}

CV. Citra Jati Jepara merupakan satu dari sekian banyak perusahaan yang bergerak dalam bidang meubel. Dimana perusahaan ini memproduksi barang berupa 
kursi dan meja tamu, lemari pakaian, lemari hias, kursi dan meja makan, meja belajar, buffet dan produk lainnya. CV. Citra Jati Jepara adalah perusahaan pribadi milik keluarga yang berlokasi di jalan Yos Sudarso No. 124 Pekanbaru, Riau yang didirikan oleh Bapak Asmuni S.Ag sejak tahun 1998 atau sekitar 20 tahun.

Besarnya Biaya Bahan Baku yang di keluarkan oleh perusahaan dalam memproduksi pesanan khusus pada CV.Citra jati JeparaTanggal 8 Juni Tahun 2016 adalah sebagai berikut:

Tabel 1. Biaya Bahan Baku untuk memproduksi pesanan khusus pada CV.Citra jati JeparaTanggal 8 Juni Tahun 2016

\begin{tabular}{|l|l|}
\hline Jenis bahan baku & Biaya per unit \\
\hline Kayu jati & Rp13.550.000.00 \\
\hline Lem kayu & Rp168.000.00 \\
\hline Cat warna kayu & Rp2.000.000.00 \\
\hline Tiner & Rp180.000.00 \\
\hline Amplas & Rp630.000.00 \\
\hline Busa & Rp1.122..000.00 \\
\hline Kain & Rp3.630.000.00 \\
\hline Kancing & Rp305.000.00 \\
\hline Tali kur & Rp181.000.00 \\
\hline Paku Pen & Rp70.000.00 \\
\hline Handle & Rp20.000.00 \\
\hline Steples etona & Rp72.000.00 \\
\hline Kaca meja & Rp750.000.00 \\
\hline Total & Rp22.678.000.00 \\
\hline
\end{tabular}

Sumber: CV. Citra Jati Jepara

Selanjutnya perusahaan merincikan biaya tenaga kerja langsung untuk produksi selamabulan Juni tahun 2016. Berikut ini merupakan biaya tenaga kerja langsung (BTKL) dalam memproduksi pesanan khusus pada CV.Citra jati JeparaTanggal 8 Juni Tahun 2016sebagai berikut.

Tabel 2. Biaya tenaga kerja langsung pesanan khusus pada CV.Citra jati JeparaTanggal 8 Juni Tahun 2016.

\begin{tabular}{|l|l|l|l|l|}
\hline Keterangan & Pekerja & $\begin{array}{l}\text { Upah per } \\
\text { Hari }\end{array}$ & $\begin{array}{l}\text { Jumlah } \\
\text { Hari } \\
\text { kerja }\end{array}$ & $\begin{array}{l}\text { Upah } \\
\text { Pesanan }\end{array}$ \\
\hline $\begin{array}{l}\text { Bagian } \\
\text { Perakitan }\end{array}$ & $\begin{array}{l}\text { Tenaga Ahli } \\
(1)\end{array}$ & Rp 100.000 & 1 & Rp100.000 \\
\cline { 2 - 5 } & $\begin{array}{l}\text { Tenaga } \\
\text { Pembantu (2) }\end{array}$ & Rp70.000 & 1 & Rp140.000 \\
\hline $\begin{array}{l}\text { Bagian } \\
\text { Finishing }\end{array}$ & $\begin{array}{l}\text { Tenaga Ahli } \\
(1)\end{array}$ & Rp 100.000 & 2 & Rp200.000 \\
\cline { 2 - 5 } & $\begin{array}{l}\text { Tenaga } \\
\text { Pembantu (1) }\end{array}$ & Rp80.000 & 2 & Rp160.000 \\
\hline $\begin{array}{l}\text { Bagian } \\
\text { Cover }\end{array}$ & $\begin{array}{l}\text { Tenaga Ahli } \\
(1)\end{array}$ & Rp 120.000 & 2 & Rp240.000 \\
\hline Total & Rp 540.000 & & Rp840.000 \\
\hline
\end{tabular}

Sumber: CV. Citra Jati Jepara
Biaya overhead pabrik dari CV. Citra Jati Jepara bisa dilihat dari tabel berikut ini.

Tabel 3. Biaya Overhead Pabrik pesanan khusus pada CV.Citra jati JeparaTanggal 8 Juni Tahun 2016.

\begin{tabular}{|l|l|l|}
\hline Jenis biaya & $\begin{array}{l}\text { Biaya per } \\
\text { unit }\end{array}$ & Total biaya \\
\hline $\begin{array}{l}\text { Minyak dan } \\
\text { oli mesin }\end{array}$ & Rp14.328,36 & Rp2.880.000 \\
\hline $\begin{array}{l}\text { Reparasi dan } \\
\text { pemeliharaan } \\
\text { mesin }\end{array}$ & Rp59.701,49 & Rp12.000.000 \\
\hline $\begin{array}{l}\text { Penyusutan } \\
\text { mesin }\end{array}$ & Rp574,42 & Rp115.458 \\
\hline $\begin{array}{l}\text { Penyusutan } \\
\text { kendaraan }\end{array}$ & Rp5.959,78 & Rp1.197.916 \\
\hline Biaya listrik & Rp26.865,67 & Rp5.400.000 \\
\hline Total & Rp107.429,72 & Rp21.593.374,00 \\
\hline
\end{tabular}

Sumber: CV.Citra Jati Jepara

Berikut merupakan Tabel Biaya non produksi pesanan khusus pada CV.Citra jati JeparaTanggal 8 Juni Tahun 2016

Tabel 4. Biaya non produksi Pesanan Khusus Tanggal 8 Juni tahun 2016

\begin{tabular}{|l|l|l|}
\hline Jenis biaya & $\begin{array}{l}\text { Biaya per } \\
\text { unit }\end{array}$ & Total biaya \\
\hline Biaya Telepon & Rp4.438,36 & Rp972.000.00 \\
\hline Total & Rp4.438,36 & Rp972.000.00 \\
\hline
\end{tabular}

\section{Sumber: CV.Citra Jati Jepara}

Berikut ini merupakan tabel perhitungan Harga Pokok Produksi Pesanan Khusus CV. Citra Jati Jepara dengan memasukkan biaya relevan saja adalah sebagai berikut.

Tabel 5. Perhitungan Harga Pokok Produksi

\begin{tabular}{|l|l|l|}
\hline Jenis Biaya & $\begin{array}{l}\text { Biaya per unit } \\
\text { Rp) }\end{array}$ & Total biaya (Rp) \\
\hline Kayu Jati & Rp13.550.000.00 & \\
\hline Lem Kayu & Rp168.000.00 & \\
\hline Cat kayu & Rp2.000.000.00 & \\
\hline Tiner & Rp180.000.00 & \\
\hline Amplas & Rp630.000.00 & \\
\hline Busa & Rp1.122..000.00 & \\
\hline Kain & Rp3.630.000.00 & \\
\hline Kancing & Rp305.000.00 & \\
\hline Tali kur & Rp181.000.00 & \\
\hline Paku Pen & Rp70.000.00 & \\
\hline Handle & Rp20.000.00 & \\
\hline Steples Etona & Rp72.000.00 & \\
\hline Kaca & Rp750.000.00 & \\
\hline $\begin{array}{l}\text { Biaya Bahan } \\
\text { Baku }\end{array}$ & & Rp22.678.000.00 \\
\hline $\begin{array}{l}\text { Biaya Tenaga } \\
\text { Kerja langsung }\end{array}$ & Rp840.000.00 & Rp840.000.00 \\
\hline Biaya & Rp250.000.00 & Rp250.000.00 \\
\hline
\end{tabular}




\begin{tabular}{|l|l|l|}
\hline Jenis Biaya & $\begin{array}{l}\text { Biaya per unit } \\
(\mathrm{Rp})\end{array}$ & Total biaya (Rp) \\
\hline Pengiriman & Rp14.328,36 & Rp14.328,36 \\
\hline $\begin{array}{l}\text { Biaya minyak } \\
\text { dan oli mesin }\end{array}$ & Rp23.782.328,36 & Rp23.782.328,36 \\
\hline $\begin{array}{l}\text { Total harga } \\
\text { pokok } \\
\text { produksi pesan } \\
\text { khusus perunit }\end{array}$ & & \\
\hline
\end{tabular}

Sumber: Olahan data (2016)

\section{PEMBAHASAN}

Berdasarkan deskripsi diatas dan penghitungan Harga Pokok Produksi Cv. Citra Jati Jepara memanfaatkan pesanan khusus ini untuk meningkatkan laba. Namun dalam pengambilan keputusan menerima atau menolak pesanan khusus, tetap menggunakan informasi analisis biaya relevan.

Pada tanggal 8 Juni 2016, perusahaan mendapatkan tawaran pesanan khusus dari pelanggan yang memesan 1 unit set kursi Royal Cempaka, 1 set Kursi Makan Ganesa dan 1 unit Buffet Salju uk 160 dengan harga Rp38.000.000.00. Perusahaan langsung saja menerima pesanan khusus tanpa perhitungan biaya relevan terlebih dahulu.Dalam keadaan ini, perusahaan di hadapkan dengan suatu pilihan di mana perusahaan ingin mendapatkan laba dari pesanan khusus tersebut.

$$
\text { Penawaran dengan harga }
$$
Rp38.000.000.00 berada di bawah harga jual normalsebesar Rp41.000.000.00 dengan menerima pesanan khusus tersebut mungkin menguntungkan bagi perusahaan. Jika pesanan tersebut di terima, perusahan sebaiknya menggolongkan biaya relevan dan biaya tidak relevan. Penggolongan biaya tersebut bermanfaat sehingga perusahaan mendapatkan laba yang relevan bagi perusahaan sehingga dapat mengoptimalkan laba pada bulan Juni 2016 tersebut.

\section{SIMPULAN}

Hasil analisis menunjukkan bahwa CV. Citra Jati Jepara dapat menerima pesanan khusus dari konsumen karena dapat memberikan keuntungan bagi perusahaan dan sesuai dengan kriteria pesanan khusus yaitu harga jual pesanan khusus lebih tinggi daripada biaya produksi.

Sebelum melakukan perhitungan terhadap harga produksi, seharusnya perusahaan mengelompokkan biaya produksi sesuai dengan prinsip akuntansi yang berlaku, yaitu melakukan pemisahan mana yang termasuk ke dalam Biaya Bahan Baku, Biaya Tenaga Kerja Langsung dan Biaya Overhead Pabrik.

\section{DAFTAR RUJUKAN}

Blocher, Katrine and Wilson, 2012.Akuntansi Manajemen. PT. Indeks, Jakarta

Dewi, Sofia P. dan Septian Bayu Kristanto, 2013, Akuntansi Biaya, In Media

FirdausA.Dunia dan Wasilah Abdullah, 2013, Akuntansi Biaya, Jakarta, Salemba Empat

Halim, Abdul et.al, 2013, Akuntansi Manajemen, Edisi ke dua, Yogyakarta, BPFE

Hansen, Don R.,Maryanne M.Mowen, 2013, Akuntansi Manajerial, Buku 2, Edisi 8, Jakarta, Salemba Empat

Hidayat, Rahmat, 2014, Analisis Penerapan Biaya Relevan Dalam Menerima Atau Menolak Pesanan Khusus Pada UD. Rezeky Bakery, Jurnal EMBA, Vol.2 No.2 Desember 2014, Hal 435-443

Kamaruddin, Ahmad, 2013. Akuntansi Manajemen Dasar-Dasar Konsep Biaya Dan Pengambilan Keputusan. Edisi Revisi Kelima. Raja Grafindo Persada, Jakarta

Krismiaji, Aryani. 2011, Akuntansi Manajemen, Edisi Kedua. UPP STIM YKPN, Yogyakarta

L.M. Samryn. 2012. Akuntansi Manajemen. PT. Kencana. Jakarta 
Macpal, Octavianus dan Ventje Ilat, 2014, Analisis Biaya Relevan Untuk Menerima Atau Menolak Pesanan Khusus Pada UD. Sinar Sakti, Jurnal EMBA, Vol.2 No.3 September 2014, Hal236-244

Mulyadi, 2012.Akuntansi Biaya. Edisi Kelima. UPP STIM YKPN, Yogyakarta

Purwaji, Agus, Wibowo dan Sabarudin Muslim, 2016, Akuntansi Biaya Edisi 2, Salemba Empat, Jakarta

Ranting, Dewanti dan, Lidia Mawikere, 2014, Penerapan Biaya Relevan dalam Pengambilan Keputusan Menerima Atau Menolak Pesanan Khusus Pada CV. Tabea, Jurnal EMBA, Vol.2 No.2 Juni 2014, Hal. 1104-1112

Rudianto, 2013.Akuntansi Manajemen Informasi untuk Pengambilan Keputusan Strategis. Erlangga, Jakarta

Salman, Kautsar. 2013. Akuntansi Biaya, Cetakan Pertama; Akademia Permarta, Jakarta

Setiawan, Temy, Ahalik, 2014, Mahir Akuntansi Akuntansi Biaya dan Manajemen, PT Buana Ilmu Populer, Jakarta

Simamora, Henry, 2012, Akuntansi Manajemen, Edisi III, Duri, Riau, Star Gate Publisher.

Siregar, Baldric, Bambang Suripto, Dody Hapsoro, Widodo Lo Eko dan Biyanto Frasto, 2013, Akuntansi Manajemen, Salemba Empat, Jakarta Selatan

Sujarweni, V.Wiratna, 2016, Akuntansi Manajemen Teori dan Aplikasi, cetakan 2016, Pustaka Baru press, Yogyakarta

Wild, Jhon dan Shaw, W. Ken.2010 edition.Manajerial Accounting. McGraw-Hill Irwin, New York.

Witjaksono, Armanto. 2011. Akuntansi Biaya. Garaha Ilmu, Yogyakarta 